\title{
Literatura y realidad: los cuentos de Después del terremoto de Murakami
}

\author{
Literature and reality: After the quake by Murakami
}

\author{
Heraclia Castellón Alcalá \\ Universidad Nacional de Educación a Distancia, España \\ heracliacastellon@gmail.com \\ Recibido: 15/10/2020. Aceptado: 11/12/2020.
}

\begin{abstract}
Resumen
Este trabajo aborda cómo el motivo argumental del terremoto de Kobe se recoge en los seis cuentos del libro Después del terremoto, que Murakami escribió tras el impacto que este suceso causó en la sociedad japonesa y en él mismo. Se trata de comprobar la forma en que el suceso real aparece en estos cuentos que se encuadran en la narrativa de Murakami más vinculada a la realidad concreta, en la que elabora un retrato crítico de una época, un acontecimiento, un movimiento social. En cada relato se estudiará la presencia del componente realista, que refleja un cuadro dantesco, y cómo influye en las conductas de los personajes. Al mismo tiempo, ha de reconocerse la aparición del componente fantástico, que, si bien es antitético del anterior, es notoriamente significativo en los relatos murakamianos. El estudio permitirá observar que la causa del seísmo se atribuye -mediante el factor fantástico- a la acción de un mal encerrado en las honduras terrestres, pero sus efectos se tratan desde el plano de lo real.
\end{abstract}

Palabras clave: cuento; literatura contemporánea; literatura japonesa

\section{Abstract}

This paper studies how the plot topic of the Kobe earthquake is represented in the six short stories included in the book After the Quake, writen by Murakami after the impact on Japanese society and himself. We will analyze how the real event appears in these short stories belonging to Murakami's narrative with stronger links with concrete reality, tales in which he presents critical portraits of an era, an event, a social movement. We will study the realistic components of Dantesque post-hecatomb pictures, and how it influences the characters' behaviors. At the same time, the fantastic component must be recognized. Although it is antithetical to the previous one, it is notoriously significant in Murakami's stories. The study will allow to observe that the cause of the earthquake 
is attributed -through the fantastic factor- to the action of an evil accumulated in the depths of the Earth; but the effects belong to reality.

Keywords: short stories; contemporary literature; Japanese literature

\section{Introducción}

Hay escritores cuyo acercamiento creativo a la ficción descansa esencialmente en un mundo literario que es un trasunto verosímil, ajustado, del mundo real; así quedó consagrado en el Realismo con los relatos decimonónicos, paradigmáticas novelas y vibrantes cuentos pensados como "espejo" stendhaliano, "un miroir que l'on promène le long d'un chemin". En la literatura española la obra narrativa de Galdós ofrece un ejemplo proverbial de acercamiento a la realidad social, a los problemas humanos y a las vidas de sus contemporáneos, quebrantadas y aquejadas por la miseria económica o moral.

En esta dirección, si bien desde una perspectiva notoriamente propia, puede entenderse que surge el libro Después del terremoto; las historias que contiene responden a un escenario real, histórico, que opera con un doloroso impacto en su autor, Haruki Murakami; es la herida lacerante que el terremoto de Kobe produjo en el país nipón lo que se pone en pie en estas fabulaciones. La narrativa de Murakami, por su parte, brinda una particular perspectiva de la sociedad japonesa de este tiempo, desde las postrimerías del siglo XX a las primeras décadas del actual. La mayoría de sus historias transcurren en Japón, si bien las referencias a la cultura occidental -música, literatura, cine-son inseparables de sus relatos. Esa coexistencia de elementos configura su quehacer literario:

Lo que hace Murakami es una asimilación más compleja que resulta, al mismo tiempo, cosmopolita e indudablemente japonesa. Se trata de un sincretismo artístico donde, no siempre con igual fortuna, se mezclan la alta cultura y la cultura pop, el racionalismo de Occidente y la imaginería del viejo Japón, las alusiones filosóficas y el melodrama, la narración convencional y el road-movie (González Torres, 2007: 41).

Sus creaciones se bifurcan en novelas y cuentos, y en ambos géneros se encuentran narraciones que recrean escenarios, criaturas, conductas y patrones sociales próximos a la realidad, plasmados a través de un molde 
expresivo ágil y fluido, sencillez elocutiva que se combina con brillantes imágenes que pueden llegar a la gracia poética. La atención con que en algunas de sus obras se recogen determinadas circunstancias sociales, sucesos históricos o movimientos surgidos en épocas concretas ha llevado a especialistas como Carlos Rubio (2012: 97) a denominarlo como "el escritor del Zenkyoto", corriente de protesta en el Japón de los años sesenta, "expresión colectiva de la insatisfacción sentida por una juventud con el modelo de rápido desarrollo económico y ajustes sociales experimentados en aquella época" (87). Esta mirada sensible a los sucesos históricos y a los fenómenos sociales que marcan las formas de vida, con todo, no es la única dirección que traza la creación de Murakami; como algo constitutivo de su prosa hay que reconocer

la presencia de dos elementos nucleares en la literatura murakamiana: por una parte, el registro cuidadoso de escenarios, entornos y rasgos afectivos atribuibles a lo real y existente, mientras que, por otro lado, irrumpe en algunas tramas la presencia de lo fantástico, de otra realidad más allá de la conocida y delimitada convencionalmente (Castellón Alcalá, 2019: 546).

A tenor de cómo se presenten estos dos elementos, sus obras se han clasificado en tipos distintos, según la "escala Murakami":

Podría hablarse de una escala de intensidad y ambición narrativa en la obra de Murakami donde cabrían tres gradaciones: las narraciones de tono realista tocadas por el misterio natural de la vida; las novelas donde la aparente cotidianidad se trastorna por el prodigio y las novelas de imaginación frenética (González Torres, 2007: 43).

Entre las obras incluidas en el primer tramo de esta escala, la preocupación por erigir una ficción que pueda ser trasunto de la realidad, estarían la novela Tokio blues (Norwegian Wood) y algunos cuentos como "Silencio" (del libro El elefante desaparece), "El folclore de nuestra generación: prehistoria del estadio avanzado del capitalismo" (de la compilación Sauce ciego, mujer dormida) y "Yesterday" (del volumen Hombres sin mujeres).

Por el contenido que lo inspira, el libro de relatos Después del terremoto se inscribe en la primera de estas dimensiones, pues surge como la 
reacción de Murakami tras el devastador terremoto que asoló Kobe en 1995; así lo revela al autor, advirtiendo que su propósito era crear un relato global, unitario, todo él configurado en torno al suceso: "Este libro contenía seis cuentos relacionados de una u otra forma con el terremoto de 1995 en Kobe. Lo escribí con la esperanza de que los seis cuentos formasen una imagen unificada en la mente del lector, así que tenía más de colección monográfica que de colección de relatos cortos" (Murakami, 2008: 8).

Pero, con todo, se da también cabida en algún relato de este conjunto a la dimensión de lo fantástico, con lo que se registra -por más que se ciña a la construcción de alguna historia- ese procedimiento fabulador del quiebro de apertura al elemento de fuera de la realidad natural, tan de cuño murakamiano, por registrarse en la mayoría de sus narraciones en las que irrumpe el prodigio, "la imaginación frenética".

El terremoto de Kobe se produjo el martes 17 enero 1995, y alcanzó 7,2 en la escala Richter. Murieron más de seis mil personas, hubo más de veinte mil heridos, y los daños materiales fueron de tremendo alcance: edificios derruidos, incendios, carreteras y vías arrasadas... La devastación provocada por esta catástrofe, así como el ataque terrorista perpetrado por una secta en el metro de Tokio el 20 de marzo del mismo año con gas sarín, movieron a Murakami a regresar a Japón, de donde se había marchado en 1986. Para los japoneses el terremoto fue una tragedia que afectó muy hondamente la conciencia colectiva (Toyohara, 2013: 234).

Después del terremoto se publica en Japón en 2000; en español, en 2013, traducido por Lourdes Porta Fuentes. En los seis relatos del libro la referencia al terremoto asume distinta entidad, nunca en primer plano de la trama; pero siempre opera en los personajes como una fuerza que los desequilibra, los empuja o acerca a la muerte, o los abduce hacia su propia oscuridad interior. Todos ellos están atenazados por el estupor, el vacío, las heridas afectivas inesperadas, el miedo, en algún caso, el pensamiento de la muerte, y la vacuidad existencial. 


\section{Los cuentos de Después del terremoto}

Después del terremoto agrupa seis cuentos, en cuyas respectivas tramas el terremoto asoma con mayor o menor presencia, pero siempre como una coordenada que altera o remueve las conductas de los personajes, de los protagonistas o de los secundarios, a veces de un modo muy indirecto, transversal. Están escritos en tercera persona, voz narrativa que Murakami adoptó tras sus primeras obras; en el primer periodo, hasta el año 2000, sus novelas y cuentos se tejían en primera persona, lo que se ha relacionado con la tradición narrativa japonesa de principios del siglo $\mathrm{XX}$ del género "novelas del yo", género a su vez influenciado por el Naturalismo europeo (Castellón Alcalá, 2020: 294). El giro a la tercera persona le permite abrir nuevas vías de construcción del relato:

A partir del año 2000, después de adquirir ese nuevo vehículo que era la tercera persona, comprendí que al fin podía adentrarme en nuevos territorios de la novela. Eso me producía una sensación de libertad, de horizonte, como si al mirar a mi alrededor las paredes que me cercaban hasta entonces se hubieran derrumbado de repente (Murakami, 2017: 229).

Desde esa nueva perspectiva narrativa que disocia al personaje del narrador transcurren estos relatos; el narrador sigue al protagonista, no se despega de sus pasos, aunque intercale, a modo de narrador omnisciente, fragmentos acerca de otros personajes secundarios, que permiten completar el perfil del protagonista. La atención a los secundarios varía en los cuentos; es especialmente relevante en "Un ovni aterriza en Kushiro", "Todos los hijos de Dios bailan", "Rana salva a Tokio" y "La torta de miel"; por el contrario, en "Tailandia" las referencias a los personajes secundarios cuentan con mucha menor entidad, si bien desde el plano de sombra en que Murakami los mantiene son decisivos en el devenir de la protagonista, y esa información que se hurta al lector confiere enorme sustancia al relato.

El primero de los cuentos, "Un ovni aterriza en Kushiro", enlaza con otras historias murakamianas a través del motivo argumental de la esposa que desaparece del domicilio conyugal en Tokio; en este caso, la esposa de 
Komura toma la decisión de irse a los cinco días del terremoto, tras el que ha quedado tan impactada que no puede sino estar plantada mirando las imágenes del cataclismo en televisión. Su marcha sume en un marasmo al protagonista, que es víctima impotente a su vez del tremendo shock que anonada a su mujer hasta el punto de decidir romper su vida en común y regresar al hogar paterno. Komura no había percibido antes la insatisfacción de su esposa; en la nota que le deja ella lo acusa de que vivir con él "es como vivir con una masa de aire". Murakami inserta pinceladas del panorama del momento, entonces de bonanza y bienestar económico: “Era una época de gran prosperidad económica, el precio del suelo subía y Japón entero rebosaba dinero. Parecía que todo el mundo tuviera la cartera repleta de billetes de diez mil yenes y unas ganas irrefrenables de gastárselos" (2017: 12).

Consumado el abandono de su esposa, la estabilidad de Komura se tambalea, y decide tomarse unas vacaciones; acepta la sugerencia / invitación de un compañero de trabajo de viajar a Hokkaido para entregar un encargo. Tanto durante el viaje como en la habitación donde está acompañado de una chica que, junto a la hermana del compañero, ha ido a recibirlo al aeropuerto, "lo que ocupaba su mente eran las escenas del terremoto. Como en una proyección de diapositivas, aparecía una, se borraba otra. Aparecía una, se borraba otra. Autopistas, llamas, humo, montañas de escombros, grietas en las calles" (Murakami, 2013: 63). El cambio de escenario no ha disipado la parálisis emocional que él también ha sufrido y su desconcierto y enajenación.

En "Rana salva a Tokio", pese a ser un cuento de corte fantástico, Murakami radiografía las nefastas secuelas de la crisis económica ligada a la explosión de la burbuja, y así registra el antes y el después del avatar financiero, en la fase de expansión:

Conceder un préstamo era algo que le apetecía a cualquiera. En especial durante la época de la burbuja financiera. En aquella época corría tanto dinero que, si el cliente tenía algún terreno o valores susceptibles de ser hipotecados, el responsable de créditos estaba dispuesto a concederle un préstamo tan elevado como quisiera (Murakami, 2013: 288). 
Cosa diferente va a ser cuando llegan las vacas flacas y quienes habían pedido préstamos no pueden devolverlos; la gestión de esos impagos y morosos es precisamente el trabajo del protagonista, Katagiri:

Sin embargo, a veces los préstamos eran irrecuperables y, en esos casos, allí estaba Katagiri para tomar las disposiciones pertinentes para conseguirlo. Su volumen de trabajo había ido aumentando con gran celeridad, sobre todo después de que estallara la burbuja. Primero había bajado la cotización de los valores en bolsa, luego, el precio del suelo. Al suceder esto, las hipotecas habían perdido su sentido original (Murakami, 2013: 289).

Ese es el ambiente en que pululan mafias y facinerosos en sus dominios, a donde Murakami dirige, centra su mirada observadora, y así describe un barrio de Tokio, escenario en el que los delincuentes campan: "El barrio Kabukichō de Shinjuku es un dédalo de violencia. Desde antiguo ha sido feudo de los yakuza; también han arraigado allí asociaciones criminales de origen coreano, además de la mafia china. Hay armas y drogas por todas partes" (Murakami 2013: 289).

Aunque sea un cuento fantástico (una rana gigante visita al protagonista para decirle que él tiene que intervenir en una lucha en el subsuelo contra una lombriz gigante para evitar que Tokio sea devastado por un pavoroso terremoto), de nuevo el reflejo de la realidad anticipada -las consecuencias de ese anunciado terremoto- cobra indudable realismo, como imágenes en eco de lo vivido:

Luego, habló Rana.

-Un gran terremoto. Asolará Tokio el dieciocho de febrero a las ocho y media de la mañana. Es decir, dentro de tres días. Aún será mayor que el de Kobe del mes pasado. Se calcula que habrá alrededor de ciento cincuenta mil muertos. La mayor parte, por descarrilamientos, vuelcos y colisiones de los medios de transporte en plena hora punta. Desplome de autopistas, hundimientos del metro, caída de ferrocarriles aéreos, explosión de camiones cisterna. Los edificios se convertirán en montañas de cascotes que sepultarán a la gente. Las llamas se alzarán por doquier. El tráfico de las carreteras quedará colapsado, las ambulancias y coches de bomberos serán meros trastos inútiles. La gente irá muriendo y muriendo, 
sin más. iCiento cincuenta mil víctimas! Un auténtico infierno. La gente deberá tomar consciencia de la fragilidad extrema de esta gran concentración de seres humanos llamada "ciudad" (Murakami, 2013: 285).

La causa del terremoto recibe aquí un tratamiento fantástico, lo genera un ser repugnante del inframundo, un gusano o lombriz gigantesco:

Gusano vive en las entrañas de la tierra. Es una lombriz enorme. Cuando se enfada, provoca terremotos -dijo Rana-. Y ahora está lleno de ira. [...] Se limita a captar con su cuerpo ecos y vibraciones que vienen de lejos, los va succionando, uno tras otro, los acumula. Luego, debido a alguna reacción química, la mayor parte de ellos se convierte en odio (Murakami, 2013: 293).

Es en este cuento donde se constata la fuga hacia lo fantástico: el personaje de Rana y su explicación sobre el modo en que el seísmo se origina. Ese vuelco en que se inserta lo que está fuera de lo real y constatable nos retrotrae a los argumentos que esgrimía Cortázar sobre el recurso a este material en la literatura, y en su literatura:

El paso de lo fantástico al realismo no es tan fácil como parece desde el momento en que nadie sabe bien exactamente qué es la realidad. [...] Aceptamos lo que nuestros sentidos nos muestran a pesar de que cualquier pequeño test muestra que nuestros sentidos se equivocan muy fácilmente. [...] Pero el concepto de la realidad es extraordinariamente permeable según las circunstancias y el punto de vista que tomemos (Bernárdez, 2013: 122).

El mismo factor de entraña fantástica -la monstruosa criatura del submundo que da lugar al terremoto- asoma parcialmente en otro cuento del libro. El cuento "Todos los hijos de Dios bailan" dio título al volumen en Japón (Toyohara, 20: 231). Al protagonista, Yoshiya, tanto su madre como su mentor espiritual le han manifestado que su padre es Dios, de quien su madre quedó embarazada, según ellos, de manera inexplicable en términos biológicos. Ha sido educado en el cristianismo, religión de la que su madre pasó a ser ferviente devota en el embarazo. La elección del nombre -deliberadamente significativo- se nos explica dentro de la tradición onomástica que se sigue en Japón, a más de su proximidad 
fonética al nombre hebreo Joshua, del que en latín se terminó formando el nombre de Jesús:

El nombre de los japoneses suele tener algún significado; normalmente dicho significado se puede comprender al leer el nombre escrito, es decir, al ver los caracteres chinos conocidos en japonés como kanji. [...]. Podríamos decir que su nombre nos anuncia que el protagonista es sin lugar a dudas una buena persona (Toyohara, 2013: 236).

El cuento recoge las dudas que asaltan al protagonista en torno a la fe; ha recibido unas creencias que han conformado su visión de la vida, pero sus experiencias personales lo acercan al descreimiento, y se cuestiona, como el san Manuel unamuniano, con profundos interrogantes la existencia de un Dios misericordioso, al que, finalmente, invoca, en paradoja igualmente unamuniana; en determinados pasajes afluye veladamente la culpabilidad por un incesto imaginado. En el momento final se atisba el recurso fugaz a lo fantástico, cuando considera el origen del terremoto, un subsuelo poblado de entes malignos que afloran furiosamente en el seísmo:

Luego, de pronto, pensó en lo que existía bajo aquel suelo que él pisaba con fuerza. Allí moraba el rugido funesto de las tinieblas profundas, moraba el negro flujo secreto que transportaba los deseos, moraba el viscoso rebullir de gusanos, moraba el cubil del terremoto que transformaba ciudades en montañas de escombros (Murakami, 2013: 198).

"La torta de miel" cierra el conjunto de relatos; el protagonista, Junpei, es escritor de cuentos; desde la universidad mantiene estrecha amistad con una pareja de amigos; siempre ha estado enamorado de la chica, Sayoko. El matrimonio, que tiene una niña, se separa y la madre acude a Junpei para tratar de calmar el insomnio de la pequeña contándole cuentos; la niña padece insomnio a causa del terremoto: en sus pesadillas "el hombre del terremoto" se le aparece y aterroriza.

De los rasgos con que se describe a Junpei, no resulta descabellado encontrar que con algunos el autor pudiera jugar a ser identificado; esos guiños -autobiográficos o no- remiten a la propia trayectoria como narrador, traductor, crítico... El terremoto ocurre cuando él está en España; 
aunque procedía de Kobe, había roto radicalmente en su juventud con su familia. Pero aun así, se siente también víctima del terremoto, que había terminado por disolver las piezas de su historia personal: "Aquella fatal catástrofe de proporciones gigantescas había alterado, de forma silenciosa pero radical, la visión de su vida cotidiana. Junpei sintió un profundo aislamiento que jamás había experimentado antes. "No tengo raíces", pensó. "No estoy ligado a nada" (Murakami, 2013: 421).

El final del relato se abre a un cambio decisivo en su vida: por fin Sayako y él establecen la relación que siempre ambos habían considerado; y ese giro personal le anima a pensar también en la creación de obras desde una nueva perspectiva vital, obras más luminosas y semejantes a la nueva vida que se abre para él. Final en positivo para la última historia del libro: "Voy a escribir otro tipo de historias", pensó Junpei. "El tipo de relatos en los que alguien aguarda, ilusionado, lleno de impaciencia, a que amanezca y el mundo se ilumine para poder abrazar con fuerza, envuelto en esta nueva luz, a los seres que ama" (Murakami, 2013: 448).

"Paisaje con plancha" quizá sea uno de los dos relatos -junto con "Tailandia"- en que la referencia al terremoto opera de modo más indirecto; no hay mención de su pavoroso alcance, de la devastación subsiguiente. Pero sí hay -como en todos los cuentos, por demásinsistencia en el tema de la muerte, aquí en relación con dos de los tres personajes que pueblan la historia, Junko y el señor Miyake, ambos fascinados por las hogueras. Ambos hablan de morir al acabar la hoguera que Miyake, talentoso montador de hogueras, ha preparado esa noche; tras conversar alrededor de la hoguera sobre la muerte, acuerdan ir en su busca. La referencia a Kobe es extremadamente escueta, al responder Miyake a las preguntas sobre su familia: "La casa está en Kobe. Es probable que todavía vivan alli". Su único interés, aparte de las hogueras, es la muerte; ese elemento recurrente es lo que engarza este relato con el resto.

"Tailandia" presenta una protagonista femenina, Satsuki, investigadora endocrinóloga, quien experimenta en propia piel los cambios hormonales propios del climaterio. Tras viajar a Bangkok para un congreso, ha decidido tomarse unas vacaciones en el norte. Al preguntarle el guía que la 
acompaña, Nimit, si vive cerca de Kobe, si conoce a alguien allí, ella responde negativamente: "No, no creo que conozca a nadie de allá -dijo ella. Pero no era cierto. En Kobe vivía aquel hombre" (228). A partir de esa vaga mención a "aquel hombre", se abre una dolorosa grieta hacia algo del pasado que aún la tortura, y que ha marcado su vida. En este cuento la atención no se detiene apenas en el terremoto, sino en la ciudad-donde vive "aquel hombre"; solo Nimit hace algún comentario acerca de ese fenómeno telúrico:

Es algo muy extraño. Me refiero a los terremotos. Nosotros estamos firmemente convencidos de que, bajo nuestros pies, la tierra es algo consistente, sólido, inamovible. Existe incluso la expresión: «Tocar de pies en el suelo». Sin embargo, un día, de repente nos damos cuenta de que no es así. La tierra y las rocas, que se suponían sólidas, se reblandecen (Murakami, 2013: 229).

Las preguntas de Nimit han removido los malos recuerdos, que suscitan su odio hacia aquel hombre por el daño causado y sus secuelas; de algún modo que no se detalla, él es el culpable de que no haya tenido hijos; su rabia se plasma en imprecaciones: “"iOjalá tu casa esté aplastada!”, pensó ella. "Y tú y toda tu familia os encontréis en la calle, sin blanca. Porque, teniendo en cuenta lo que tú has hecho con mi vida, teniendo en cuenta los hijos que yo debería haber tenido, eso es lo que te mereces»" (Murakami 2013: 236).

El terremoto provoca que las heridas del pasado se hayan reabierto. Quizá por eso el relato se cierra con un final en cierta medida reparador. Nimit la conduce el último día a una mísera cabaña, donde una anciana adivina escruta y descubre algo muy doloroso de su pasado, "una piedra dentro de usted. Una piedra blanca y dura", pero a la vez le explica cómo puede liberarse de ella a través de un sueño; y termina con una noticia y un mensaje esperanzador: "Ese hombre no está muerto -tradujo Nimit-. No ha sufrido ni un rasguño. Quizá no sea esto lo que usted deseaba, pero para usted es mejor así. Debe agradecer su buena suerte" (Murakami, 2013: 258). 


\section{Referencias}

Bernárdez, Aurora y Carlos Álvarez Garriga (eds.) (2013). Julio Cortázar. Clases de literatura. Berkeley 1980. Buenos Aires: Aguilar, Altea, Taurus, Alfaguara.

Castellón Alcalá, Heraclia (2019). "Lo real y lo fantástico en los cuentos de Sauce ciego, mujer dormida de Murakami". Sincronía, vol. 23, n. 76. 545-562. Disponible en: https://www.redalyc.org/jatsRepo/5138/513859856027/513859856027.pdf

Castellón Alcalá, Heraclia (2020). "El universo narrativo de Haruki Murakami en algunos cuentos de Hombres sin mujeres". Literatura: teoría, historia, crítica, vol. 22, n. 1. 271-305. Disponible en: https://revistas.unal.edu.co/index.php/lthc/article/view/82300

González Torres, Armando (2007). "Haruki Murakami: Los centros excéntricos". Quimera, n. 289, dic. 41-43. Disponible en: http://sobreperdonar.blogspot.com/2012/10/harukimurakami-los-centros-excentricos.html

Murakami, Haruki (2008). Sauce ciego, mujer dormida. Barcelona: Tusquets.

Murakami, Haruki (2013). Después del terremoto. Barcelona: Tusquets.

Murakami, Haruki (2017). De qué hablo cuando hablo de escribir. Barcelona: Tusquets.

Rubio, Carlos (2012). El Japón de Murakami. Madrid: Aguilar.

Toyohara, Hitomi (2015). “Análisis de la traducción española de un relato de Haruki Murakami: "Todos los hijos de Dios bailan". Anuario de Literatura Comparada, n. 5. 231252. Disponible en:

https://gredos.usal.es/bitstream/handle/10366/128042/Analisis de la traduccion espan ola_de_un.pdf;jsessionid=D04E084A2B9E0C750538E775A122D84A?sequence $=1$ 